\title{
The influence of circuit training on the development of strength and speed-power abilities in basketball players of 18-19 years old
}

\author{
Strelnikowa I.V. ${ }^{1 \mathrm{ABC}}$ Polevoy G.G. ${ }^{2 \mathrm{DE}}$ \\ ${ }_{1,2}^{2}$ Department of physical education, Vyatka State University, Kirov, Russia
}

Authors' Contribution: A - Study design; B - Data collection; C - Statistical analysis; D - Manuscript Preparation; E - Funds Collection.

\begin{abstract}
Purpose: $\quad$ to determine the influence of circuit training on the level of strength and speed-strength abilities development in basketball players of 18-19 years old at the pre-competitive and competitive stages of the training process.

Material: $\quad$ athletes $(n=32)$ were divided into 2 groups of 16 people. The pedagogical experiment lasted 7 months. Tests were applied to determine speed-power abilities: standing long jump test (broad jump, $\mathrm{cm}$ ); vertical jump test. Strength was evaluated by the following tests: pull-up bars; hanging leg raises (stall bars).

Results: $\quad$ it was determined that power and speed-power abilities are leading in basketball. It was proposed the set of physical exercises performed on the principle of circuit training. It was confirmed the expediency of the circuit training applying for the development of power and speed-power abilities in basketball players. It is established that the circular training in the preparatory and final parts of the training increases the speed and speed-strength indicators of basketball players.

Conclusions: It is recommended the circuit training applying at the pre-competitive and competitive stages of the training process.

Keywords: basketball, circuit training, strength abilities, speed-strength abilities, athletes.
\end{abstract}

\section{Introduction}

Power and speed-power abilities are one of the leading components of basketball players' physical fitness. The high level of their development has a positive effect on the physical and technical readiness of athletes [1-3]. The most favorable period for the development of strength abilities in males is age after 16 years. The most favorable period for the development of speed abilities is observed much earlier $[4,5]$. Therefore, the age of 18-19 years can be considered favorable for the experiment.

In the modern scientific literature was accumulated extensive knowledge devoted to the peculiarities of the strength and speed qualities development in athletes of various sports in the course of many years of training [69]. Numerous publications provide experimental data on the peculiarities of the various training modes influence and the human body responses to the performance of power and speed loads [10-13].

However, the generally accepted forms of training organization become the same type and familiar to the athletes. Therefore, it is necessary to search for new forms and promising approaches to the training process organization. Such an approach is especially important in the pre-competitive and competitive stages.

Circuit training is one of the modern forms of exercise. Such training effectively solves the problems of the interconnected development of physical qualities, strength and speed-strength abilities. Performing the usual training motor actions in a circle allows you to repeat them repeatedly and in a complex with a large motor density [14].

Circuit training sets are widespread in sports, among schoolchildren and overweight people [15-18]. In basketball, there are studies that confirm the effectiveness of the circuit training applying in the training process [19, 20].

The purpose of the work is to determine the influence of circuit training on the level of development of power and speed-power abilities of basketball players of 18-19 years old at the pre-competitive and competitive stages of the training process.

\section{Material and methods}

Participants: Basketball players took part in the study ( $\mathrm{n}=32$, age - 18-19 years old). The athletes were divided into 2 groups: control (CG) and experimental (EG). The study lasted 7 months.

Procedure:

Control tests were performed at the beginning and at the end of the experiment according to the following tests: standing long jump; vertical jump; pull-up bars; hanging leg raises (stall bars) [21, 22].

Circular training was applied in the EG during the preparatory and final parts of the training: in the precompetition period - 2 times a week; in the competitive period - once a week. The group was divided into 4 subgroups, which were located in different sectors. The peculiarity of the experiment was that EG athletes moved from one sector to another with a basketball ball. The flow method was applied. In the first sector, the athletes carried out the following tasks: barrier jumps single leg (low barriers) (20 push-offs with each foot); high bar squat vs. low bar squat (10-20 times ); rope jumps (100-150 times); vertical jumps with a touch of a basketball hoop (10 jumps). In the second sector, exercises with a bar were performed (weight was $30-40 \%$ of the athlete's weight): close grip barbell bench press) (up to $50 \mathrm{~cm}$ ) - 5x5 times; seated barbell military press - $5 \times 5$ times; calf raise in standing position - 2x20 times; incline bench press (45 
degrees) - 5x5 times. In the third sector, the following exercises were performed: barrier jumps single leg (20 push-offs each foot); box jumps down (60 cm height) followed by a vertical jump with a touch of a basketball hoop; shots (distance to the basketball backboard was 1.5 meters, 15-20 shots). In the fourth sector, the following exercises were performed: eurofit sit up test (hands with the ball are placed in front of the chest) - 2x10 times; single leg lateral barrier jump, low barriers) (20-30 pushoffs); parallel bar dips - 3x5 times.

Statistical analysis:

The results were processed in Excel (Student's t- test, the result was significant at $\mathrm{p}<0.05$ ).

\section{Results}

The level of athletes was about the same in comparison of the initial indicators. The differences between the groups were not significant $(\mathrm{p}>0.05)$. The analysis of the results revealed that a positive trend was observed in all tests of the EG and the CG groups. However, the dynamics of their changes was different (Table 1).

In the test "Standing long jump" the result improved: in the EG from $247.6 \pm 2.81$ (at the beginning of the experiment) to $269.6 \pm 2.76$ (at the end of the experiment). The result improved in the CG from $244.15 \pm 3.93$ (at the beginning of the experiment) to $256.1 \pm 2.93$ (at the end of the experiment). The increase in the test result is significant in both groups $(\mathrm{p}<0.05)$. However, at the end of the experiment, athletes from the EG were ahead in the athletes' test result from the $\mathrm{CG}(\mathrm{t}=3.38$; $\mathrm{p}<0.05)$.

The indicators in the test "Vertical jump" also increased in both groups: in the EG - from $60.7 \pm 3.2$ to $67.06 \pm 3.3(\mathrm{p}<0.05)$; in the CG - from $61.6 \pm 2.53$ to $63.5 \pm 3.85$ (the result is unreliable, $p>0.05$ ). Intergroup comparison showed significantly reliable results for the athletes of EG $(\mathrm{t}=2.4 ; \mathrm{p}<0.05)$.

Significantly reliable changes revealed in both groups in the "Pull-up bars" test: in the EG - from $9.4 \pm 0.63$ to $13.0 \pm 0.62(\mathrm{p}<0.05)$; in the $\mathrm{CG}-$ from $8.9 \pm 0.69$ to $10.8 \pm 0.62$ (the result is unreliable, $\mathrm{p}>0.05$ ). The resulting difference in the increase of groups' indicators is significantly reliable for the $E G(t=2.5 ; p<0.05)$.

The result improved in both groups in the test "Hanging leg raises (stall bars)". In the EG, the increase was from $11.3 \pm 0.66$ to $20.5 \pm 1.27(\mathrm{p}<0.05)$. In the $\mathrm{CG}-$ from $12.2 \pm 1.04$ to $12.6 \pm 1.12$ (the result is unreliable, $\mathrm{p}>$ $0.05)$. The final comparison at the end of the experiment revealed the advantage of the EG $(t=4.66 ; \mathrm{p}<0.05)$.

The results analysis of the final test revealed that the athletes of the EG were significantly ahead of the athletes of CG in all tests $(\mathrm{p}<0.05)$.

These data confirm that the increase in all indicators during the experiment was significantly higher in the EG than in the CG. This is a strong argument in favor of the circuit training applying for basketball players of 18-19 years old at the pre-competitive and competitive stages of the training process.

\section{Discussion}

At the present stage of basketball development, the increased sportsmanship requires technical skills from athletes for competitive actions and the concentrated development of physical qualities. The main elements of most integral motor actions in basketball are speed and strength [3, 22-23]. With the simultaneous improvement of strength and speed in terms of training the jumping ability is also improved. The jumping ability is a form of speed-power abilities expression [24-27]. The need for local effects on certain sets of muscles increases to provide the necessary strength and speed-strength training [28-31]. The following exercises are performed in this training where the power abilities reach a maximum by increasing the speed of muscle contraction: rope jumping; "Short" and "long" jumps over barriers; exercises with bar; squats; exercises with small weights bar [32].

The effectiveness of the circuit training applying is complex. It helps to increase athletes' skills, to fight actively against obesity, and to develop the physical qualities in children and adults [15-18]. The generalization of experimental data allows us to conclude that it is advisable to apply the sets of circuit training for athletes at different stages of readiness. This approach is effective in

Table 1. Comparative analysis of indicators in basketball players of 18-19 years old

\begin{tabular}{|c|c|c|c|c|}
\hline Indicators & Group & $\begin{array}{l}\text { Before } \\
\text { experiment }\end{array}$ & After experiment & $t ; p$ \\
\hline & EG & $247.6 \pm 2.81$ & $269.6 \pm 2.76$ & $t=5.59 ; p<0.05$ \\
\hline \multirow[t]{3}{*}{ Standing long jump (cm) } & CG & $244.15 \pm 3.93$ & $256.1 \pm 2.93$ & $\mathrm{t}=\mathbf{2 . 3 9} ; \mathrm{p}<0.05$ \\
\hline & $t ; p$ & $t=0.74 ; p>0.05$ & $t=3.38 ; p<0.05$ & - \\
\hline & EG & $60.7 \pm 3.2$ & $67.06 \pm 3.3$ & $t=2.6 ; p<0.05$ \\
\hline \multirow[t]{3}{*}{ Vertical jump (cm) } & CG & $61.6 \pm 2.53$ & $63.5 \pm 3.85$ & $t=1.23 ; p>0.05$ \\
\hline & $t ; p$ & $t=0.74 ; p>0.05$ & $t=2.4 ; p<0.05$ & - \\
\hline & EG & $9.4 \pm 0.63$ & $13.0 \pm 0.62$ & $t=4.07 ; p<0.05$ \\
\hline \multirow[t]{3}{*}{ Pull-up bars (times) } & CG & $8.9 \pm 0.69$ & $10.8 \pm 0.62$ & $t=2.04 ; p>0.05$ \\
\hline & $t ; p$ & $t=0.54 ; p>0.05$ & $t=2.5 ; p<0.05$ & - \\
\hline & EG & $11.3 \pm 0.66$ & $20.5 \pm 1.27$ & $t=6.42 ; p<0.05$ \\
\hline \multirow[t]{2}{*}{ Hanging leg raises (stall bars) (times) } & CG & $12.2 \pm 1.04$ & $12.6 \pm 1.12$ & $t=0.26 ; p>0.05$ \\
\hline & $\mathrm{t} ; \mathrm{p}$ & $t=0.73 ; p>0.05$ & $t=4.66 ; p<0.05$ & - \\
\hline
\end{tabular}


basketball [19-20]. Currently, the volume of training and competitive loads has increased significantly. It doesn't always correspond to the level of athletes' physical fitness. We have proposed to perform a set of physical exercises for the development of strength and speedstrength abilities in basketball players of 18-19 years old (circuit training). The performance of such exercises is most effective at the pre-competitive and competitive stages of the training process.

We have proposed another organizational scheme for circuit training:

- The alternation of four sectors, in which there were also four "stations" (tasks). Athletes performed all activities in each sector and then moved to another sector.

- Athletes were evenly distributed across all sectors and at the same time began to perform exercises.

- Moving from one sector to another the athletes drive the ball.

- Athletes performed maximum intensity exercises 1-2 times a week.

Thus, the purpose of the research is achieved and confirmed by the results of a pedagogical experiment.

\section{Conclusion}

The obtained data are confirmed by the results of the experiment and indicate a significant effect of the circular training on the absolute improvement of all the studied indicators in the EG. The results of the study are new, relevant and promising for further study. The circuit training at different stages of many years training is recommended for coaches.

\section{Conflict of interest}

The authors declare that there is no conflict of interests.

\section{References}

1. BenAbdelkrimN,ElFazaaS,ElAtiJ.Time-motionanalysisand physiological data of elite under-19-year-old basketball players during competition. Literature Review. 2007;41(2):69-75. https://doi.org/10.1136/bjsm.2006.032318

2. Cronin JB, Hansen, KT. Strength and power predictors of sports speed. J Strength Cond Res. 2005;19(2):349-357 https://doi.org/10.1519/14323.1

3. Pojskić H, Šeparović V, Muratović M, Uièanin E. The relationship between physical fitness and shooting accuracy of professional basketball players. Motriz. Revista de Educacao Fisica. 2014;4(20):408-417. https://doi.org/10.1590/S1980-65742014000400007

4. Castagna C, Abt G, Manzi V, Annino G, Padua E, D'Ottavio S. Effect of recovery mode on repeated sprint ability in young basketball players. Journal of Strength and Conditioning Research. 2008;22(3):923-929. https://doi.org/10.1519/JSC.0b013e31816a4281

5. Te Wierike SCM., De Jong MC, Tromp EJY, Vuijk PJ, Lemmink KAPM, Malina RM, Elferink-Gemser MT, Visscher C. Development of repeated sprint ability in talented youth basketball players. Journal of Strength and Conditioning Research. 2014;4(28):928-934. https://doi.org/10.1097/JSC.0000000000000223

6. Chelly MS, Fathloun M, Cherif N, Ben Amar M, Tabka Z, Van Praagh E. Effects of a back squat training program on leg power, jump, and sprint performances in junior soccer players. J Strength Cond Res. 2009;8(23):2241-2249. https://doi.org/10.1136/bjsm.2006.032318

7. Gabbett T, Johns J, Riemann M. Performance changes following training in junior rugby league players. $J$ Strength Cond Res In press. 2008;22(3):910-917. https://doi.org/10.1519/JSC.0b013e31816a5fa5

8. Lockie RG, Murphy AJ, Knight TJ, Janse de Jonge XA. Factors that differentiate acceleration ability in field sport athletes. Journal of Strength and Conditioning Research. 2011;25(10):2704-2714. https://doi.org/10.1519/JSC.0b013e31820d9f17

9. Loturco I, Nakamura FY, Kobal R, Gil S, Cal Abad CC, Cuniyochi R, Pereira LA, Roschel H. Training for power and speed: Effects of increasing or decreasing jump squat velocity in elite young soccer players. Journal of Strength and Conditioning Research. 2015;10 (29):2771-2779.
https://doi.org/10.1519/JSC.0000000000000951

10.Fort-Vanmeerhaeghe A, Montalvo A, Latinjak A, Unnithan V. Physical characteristics of elite adolescent female basketball players and their relationship to match performance. Journal of Human Kinetics. 2016;53(53):167-178. https://doi.org/10.1515/hukin-2016-0020

11. Gabbett T, Kelly JN, Sheppard JM. Speed, change of direction speed, and reactive agility of rugby league players. J Strength Cond Res. 2008;22(1):174-181. https://doi.org/10.1519/JSC.0b013e31815ef700

12.Kirby TJ, Erickson T, McBride JM. Model for progression of strength, power, and speed training. Strength and Conditioning Journal. 2010;5(32):86-90. https://doi.org/10.1519/SSC.0b013e3181f3ee5d

13.Padulo J, Tabben $\mathrm{M}$, Ardigò LP, Ionel M, Popa C, Gevat C, Zagatto AM, Dello Iacono A. Repeated sprint ability related to recovery time in young soccer players. Research in Sports Medicine. 2015;4(23):412-423. https://doi.org/10.1080/15438627.2015.1076419

14.Gotshalk LA, Berger RA \& Kraemer WJ. Cardiovascular responses to a high-volume continuous circuit resistance training protocol. Journal of Strength and Conditioning Research. 2004;18;4:760-64. https://doi.org/10.1519/14954.1

15.Mayorga-Vega D, Viciana J, Cocca A. Effects of a Circuit Training Program on Muscular and Cardiovascular Endurance and their Maintenance in Schoolchildren. $J$ Hum Kinet. 2013;37:153-160. https://doi.org/10.2478/hukin-2013-0036

16.Paoli A, Pacelli QF, Moro T, Marcolin G, Neri M, Battaglia G, Sergi G, Bolzetta F, Bianco A. Effects of high-intensity circuit training, low-intensity circuit training and endurance training on blood pressure and lipoproteins in middleaged overweight men. Lipids Health Dis. 2013;12:131. https://doi.org/10.1186/1476-511X-12-131

17.Solanki R, Bhise A, Shukla Y, Prabhakar M. Effects of high intensity circuit training using body weight on aerobic fitness and muscular endurance in college students. Physiotherapy. 2015;101:1418-1419. https://doi.org/10.1016/j.physio.2015.03.1373

18. Miller MB, Pearcey GEP, Cahill F, McCarthy H, Stratton SBD, Noftall JC, Buckle S, Basset FA, Sun G, Button DC. The Effect of a Short-Term High-Intensity 
Circuit Training Program on Work Capacity, Body Composition, and Blood Profiles in Sedentary Obese Men: A Pilot Study. BioMed Research International. 2014;10. https://doi.org/10.1155/2014/191797

19.Freitas TT, Calleja-González J, Alarcón F, Alcaraz PE. Acute effects of two different resistance circuit training protocols on performance and perceived exertion in semiprofessional basketball players. J Strength Cond Res. 2016;2;30:407-414. https://doi.org/10.1519/JSC.0000000000001123

20.Marcolin G, Camazzola N, Panizzolo FA, Grigoletto D, Paoli A. Different intensities of basketball drills affect jump shot accuracy of expert and junior players. PeerJ. 2018;6:42-50. https://doi.org/10.7717/peerj.4250

21.Eurofit: handbook for the Eurofit tests of physical fitness, 2nd Edition, Strasbourg; 1993.

22.Read PJ, Hughes J, Stewart P, Chavda S, Bishop C, Edwards M, Turner AN. A needs analysis and field-based testing battery for basketball. Strength and Conditioning Journal. 2014;3(36):13-20. https://doi.org/10.1519/SSC.0000000000000051

23.Te Wierike SCM, Elferink-Gemser MT, Tromp EJY, Vaeyens $\mathrm{R}$, Visscher C. Role of maturity timing in selection procedures and in the specialisation of playing positions in youth basketball. Journal of Sports Sciences. 2015;4(33):337-345. https://doi.org/10.1080/02640414.2014.942684

24.Kawamori N, Haff GG. The optimal training load for the development of muscular power. Journal of Strength and Conditioning Research. 2004;3(18):675-684. https://doi.org/10.1519/1533-4287(2004)18<675:TOTLFT> 2.0.CO;2

25.Ronnestad BR, Kvamme NH, Sunde A, Raastad T. Shortterm effects of strength and plyometric training on sprint and jump performance in professional soccer players. Journal of Strength and Conditioning Research. 2008;3(22):773-780. https://doi.org/10.1519/JSC.0b013e31816a5e86
26.StylesWJ,MatthewsMJ,ComfortP.EffectsofStrength Training on Squat and Sprint Performance in Soccer Players. Journal of Strength and Conditioning Research . 2016;6(30):1534-1539. https://doi.org/10.1519/JSC.0000000000001243

27.Tricoli V, Lamas L, Carnevale R, Ugrinowitsch C. Shortterm effects on lower-body functional power development: Weightlifting vs. vertical jump training programs. Journal of Strength and Conditioning Research. 2005;2(19):433-437. https://doi.org/10.1519/R-14083.1

28.Alemdaroğlu U. The Relationship Between Muscle Strength, Anaerobic Performance, Agility, Sprint Ability and Vertical Jump Performance in Professional Basketball Players. Journal of Human Kinetics. 2012;1(31):149-158. https://doi.org/10.2478/v10078-012-0016-6

29.Comfort P, Stewart A, Bloom L, Clarkson B. Relationships between strength, sprint, and jump performance in well-trained youthsoccerplayers.JStrengthCondRes.2014;28(1):173-177. https://doi.org/10.1519/JSC.0b013e318291b8c7

30.Hori N, Newton RU, Kawamori N, Mcguigan MR, Andrews WA, Chapman DW, Nosaka K. Comparison of weighted jump squat training with and without eccentric braking. Journal of Strength and Conditioning Research. 2008;1(22):54-65. https://doi.org/10.1519/JSC.0b013e31815ef052

31.Sáez de Villarreal E, Requena B, Izquierdo M, GonzalezBadillo JJ. Enhancing sprint and strength performance: Combined versus maximal power, traditional heavyresistance and plyometric training. Journal of Science and Medicine in Sport. 2013;2(16):146-150. https://doi.org/10.1016/j.jsams.2012.05.007

32.Hansen K, Cronin J. Training loads for the development of lower body muscular power during squatting movements. Strength and Conditioning Journal. 2009;3(31):17-33. https://doi.org/10.1519/SSC.0b013e3181957065

\section{Information about the authors:}

Strelnikowa I.V.; http://orcid.org/0000-0002-2715-7513; irina.strelnikowa2017@yandex.ru; Department of physical education. Vyatka State University; Moscow str., 36, Kirov, 610000. Russia.

Polevoy G. G.; (Corresponding author); http://orcid.org/0000-0002-3300-3908; g.g.polevoy@gmail.com; Department of physical education. Vyatka State University; Moscow str., 36, Kirov, 610000. Russia.

\section{Cite this article as:}

Strelnikowa IV., Polevoy GG. The influence of circuit training on the development of strength and speed-power abilities in basketball players of 18-19 years old. Physical education of students, 2019;23(2):89-92. https://doi.org/10.15561/20755279.2019.0206

The electronic version of this article is the complete one and can be found online at: https://sportedu.org.ua/index.php/PES/issue/archive

This is an Open Access article distributed under the terms of the Creative Commons Attribution License, which permits unrestricted use, distribution, and reproduction in any medium, provided the original work is properly cited http://creativecommons.org/licenses/by/4.0/deed.en

Received: 22.02.2019

Accepted: 25.03.2019; Published: 28.04.2019 